\title{
Research on the power generation performance of eccentric rotor type wave energy generation device under different wave conditions
}

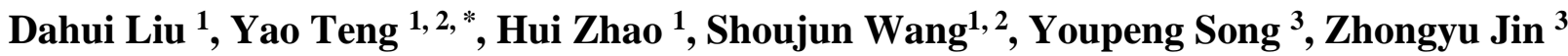 \\ ${ }^{1}$ CIMC Offshore Engineering Institute Co., Ltd., Yantai, China \\ ${ }^{2}$ College of Power and Energy Engineering, Harbin Engineering University, Harbin, China \\ ${ }^{3}$ College of Shipbuilding Engineering, Harbin Engineering University, Harbin, China \\ *Corresponding author: daweiping@126.com
}

Keywords: Wave energy generator, eccentric rotor, power generation performance, different wave conditions.

\begin{abstract}
Wave energy is an important clean renewable energy source for the ocean, and is of great importance for development. However, it is difficult to achieve the unity of high efficiency and high reliability of existing wave energy development devices. In this paper, a new form of fully enclosed eccentric pendulum wave energy generation device is proposed. A hydrodynamic model based on AQWA software, a mechanism dynamics model based on Adams software, and a hydraulic energy conversion system model based on AMESim software are developed to analyze the motion response and power generation performance of the device under different wave excitation conditions. The results show that the wave excitation conditions and the rotor eccentricity jointly affect the power generation performance of the wave energy generation device, and the high efficiency of wave energy capture can be obtained by real-time adjustment of the rotor eccentricity. This paper both exploits the high reliability of the fully enclosed structure and proposes a control strategy to achieve efficient energy conversion, laying the foundation for the development of a wave energy generation device with both high efficiency and high reliability.
\end{abstract}

\section{Introduction}

The development and utilization of marine renewable energy is conducive to promoting the synergistic development of seawater desalination [1], aquaculture [2], island development [3], marine military construction and other fields, and will play an important role in improving the energy structure and promoting economic development. According to the International Renewable Energy Agency (IRENA), the installed capacity of global marine energy installations will reach 10GW by 2030, which is 20 times of the current total installed capacity [4], and marine energy has great potential for development in the future.

Wave energy is an important marine renewable energy source. After decades of efforts, scientists have preliminarily solved the wave formation mechanism [5], resource distribution [6], energy conversion methods [7], and principle prototype verification [8], and developed different types of wave energy generation devices such as oscillating water column type [9], point absorption type [10], and wave crossing type [11], and wave energy development activities are gradually focusing on the promotion and commercialization of development technologies The wave energy development activities are gradually focusing on the promotion and commercialization of development technologies.

However, the high efficiency and reliability of wave energy generation devices are mutually constrained. In terms of energy density of wave energy, the distant sea area is larger than the offshore sea area, and it is more favorable to obtain higher energy conversion efficiency in the distant sea area, but it also faces harsher sea conditions, high equipment maintenance costs, and poor reliability [12]; in terms of energy capture method, the wave direct-driven primary energy capture mechanism can obtain higher energy conversion efficiency, but the relative moving parts of the energy capture 
mechanism are often corroded by high salt and high humidity [13], which leads to lower equipment reliability and cannot work stably for a long time. However, the relative moving parts of the energy capture mechanism are often corroded by high salt and high humidity in the marine environment [13], which leads to lower reliability of the equipment and cannot work stably for a long time.

In order to solve the above problems, this paper proposes a new form of Eccentric Rotating Wave Energy Converter (ERWEC), taking into account the constraints between energy output efficiency and equipment reliability. In Section 2, the simulation model of the wave energy generator is established; in Section 3, the variable eccentric distance control strategy of the eccentric rotor is established; in Section 4, the motion response of the wave energy generator under wave excitation is analyzed; in Section 5, the power generation performance of the generator under different wave excitation conditions is analyzed; finally, the whole paper is summarized and future research directions are indicated.

\section{Simulation model of wave energy generation device}

The built-in eccentric rotor wave power generator adopts a fully enclosed floating body structure, and the hydrodynamic performance simulation model of ERWEC is built in AQWA software, as shown in Fig. 1. Meanwhile, the mechanism dynamics simulation model of ERWEC is established in Adams software, as shown in Fig. 2. The total mass of ERWEC is $464 \mathrm{~kg}$, the mass of eccentric rotor is $20 \mathrm{~kg}$, the draught depth is $0.45 \mathrm{~m}$, the lower casing is a semi-ellipsoidal ball with $2 \mathrm{~m}$ long axis, $1.1 \mathrm{~m}$ short axis and $0.55 \mathrm{~m}$ height, and three mooring chains with $11 \mathrm{~mm}$ diameter are used. The eccentric rotor can slide along the connecting rod and the maximum eccentricity is $0.26 \mathrm{~m}$. The joint simulation of AQWA and Adams is realized by taking the six degrees of freedom motion of the ERWEC shell, the resistance moment between the eccentric rotor and the central axis, and the eccentricity of the eccentric rotor as the input and the speed of the eccentric rotor as the output under the wave excitation.

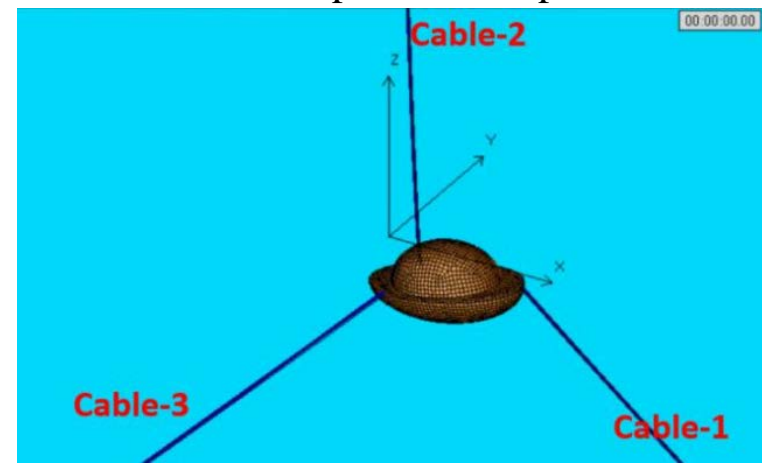

Figure 1. Hydrodynamic analysis model based on AQWA

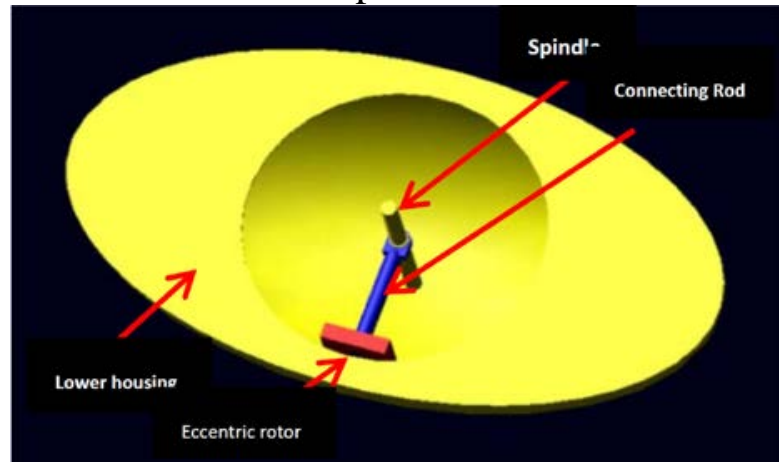

Figure 2. Adams-based mechanism dynamics analysis model

Further, a simulation model of the hydraulic energy conversion (Power-Take-Off, PTO) system of ERWEC was built in AMESim software, as shown in Figure 3, for calculating the energy conversion efficiency of the wave energy generation device. 


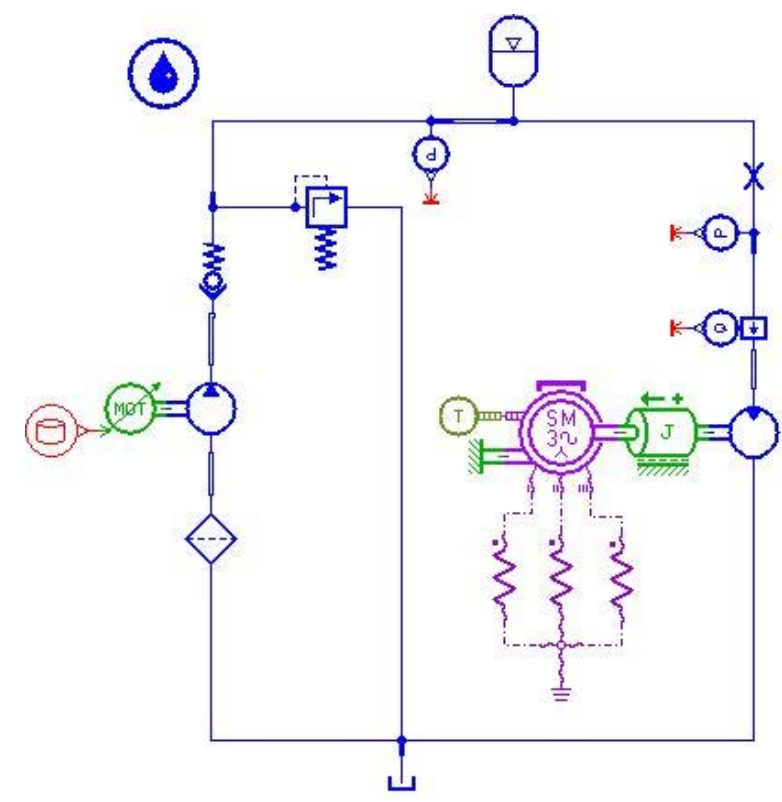

Figure 3. Analytical model of hydraulic PTO system based on AMESim

The output power of the hydraulic pump is:

$$
P_{p}=\frac{P Q}{60}
$$

Where $P$ is the output pressure of the hydraulic pump and $Q$ is the output flow rate of the hydraulic pump.

The output power of the hydraulic motor is:

$$
P_{m}=9550 n_{\text {motor }} T_{n}
$$

Where, $n_{\text {motor }}$ is the hydraulic motor speed, $T_{n}$ is the hydraulic motor resistance torque. During the simulation, the parameters of the AMESim model are set as shown in Table 1.

Table 1. Parameter settings of AMESim model

\begin{tabular}{cc}
\hline Type & Parameters \\
\hline Hydraulic Pumps & Displacement of $15 \mathrm{ml} / \mathrm{r}$ \\
Safety valves & Opening pressure is $21 \mathrm{MPa}$ \\
Accumulator & Pre-inflation pressure $15 \mathrm{MPa}$, volume $3 \mathrm{~L}$, minimum working pressure \\
& $1 \mathrm{MPa}$ \\
Hydraulic Motor & Displacement $8.2 \mathrm{ml} / \mathrm{r}$ \\
Mechanical load & Torque coefficient: $0.0001 \mathrm{NM} /(\mathrm{r} / \mathrm{min})$, rotational inertia $1 \mathrm{kgm}^{2}$ \\
Generators & Number of pole pairs 6, resistance $0.25 \Omega$, inductance $0.01 \mathrm{H}$, magnetic flux \\
Power generation & $0.735 \mathrm{~Wb}$, rated power $10 \mathrm{KW}$ \\
load & Three 100 ohm resistors in parallel \\
\hline
\end{tabular}

\section{Variable eccentricity control strategy}

The eccentricity of the eccentric rotor in an ERWEC device is a key factor affecting the power generation performance. In engineering applications, the eccentricity of the eccentric rotor can be dynamically adjusted with a small driving force to obtain the best wave energy capture effect. To facilitate the analysis of the effect of eccentricity on the energy capture effect, a joint simulation model of Adams and Simulink is established, as shown in Fig. 4. Further, to realize the stable rotation of the eccentric rotor under the wave excitation, an eccentric rotor energy capture controller based on PID 
algorithm is established to achieve the tracking control of the desired eccentric rotor speed by adjusting the eccentric distance in real time, as shown in Fig. 5.

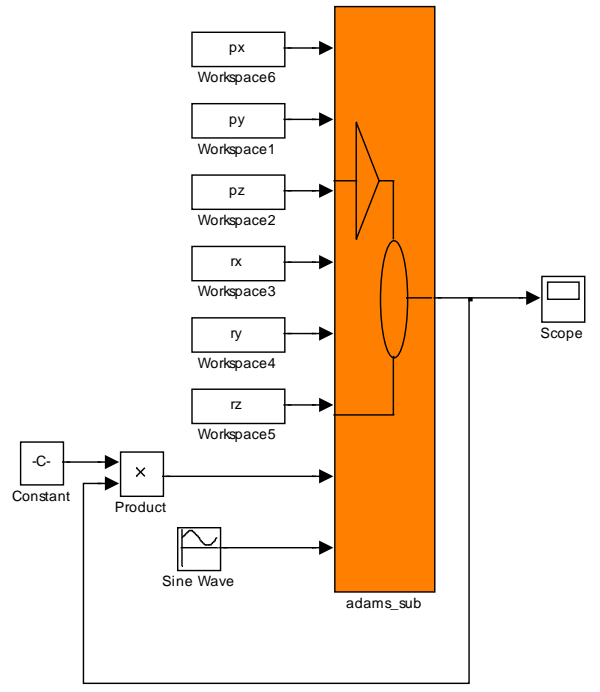

Figure 4. Joint Simulation Model of Adams and Simulink

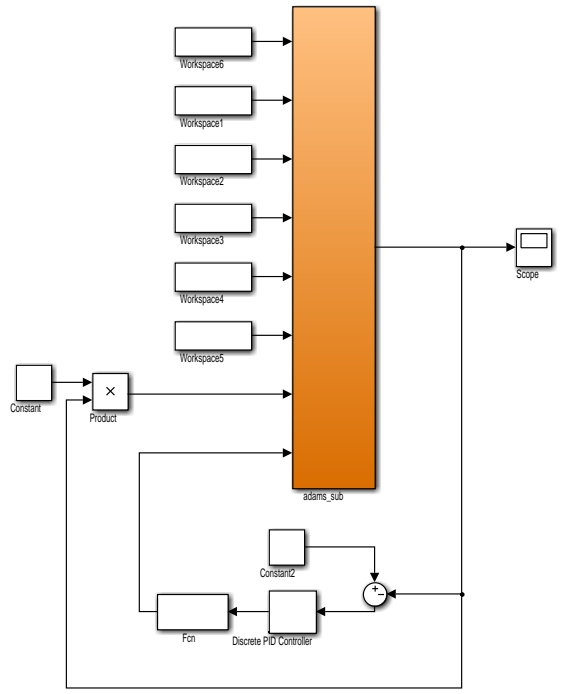

Figure 5. eccentric rotor energy capture controller Wave Energy Generator

Set different resistive moments between eccentric rotor and central shaft, different eccentric distances of eccentric rotor respectively, and construct 12 sets of arithmetic cases, as shown in Table 2 , to analyze the output speed of eccentric rotor. Among them, the resistive torque is set to be positively correlated with the rotational speed, that is, the faster the rotational speed is, the larger the resistive torque is to simulate the linear change of the generating load, and the scale factor $K_{T W}$ is set as the resistive torque coefficient.

Table 2. parameter settings for numerical simulation analysis

\begin{tabular}{ccccc}
\hline & $\begin{array}{c}\text { Effective wave } \\
\text { height }\end{array}$ & $\begin{array}{c}\text { Average wave } \\
\text { period }\end{array}$ & $K_{T W}$ & $\begin{array}{c}\text { Eccentric distance variation } \\
\text { law }\end{array}$ \\
\hline Example A & $1.5 \mathrm{~m}$ & $6 \mathrm{~s}$ & 0 & 0.06 \\
Example B & $1.5 \mathrm{~m}$ & $6 \mathrm{~s}$ & 0.25 & $0.13 \sin (0.5 t-\pi / 2)+0.13$ \\
Example C & $1.5 \mathrm{~m}$ & $6 \mathrm{~s}$ & 0.25 & $0.1 \sin (0.5 t-\pi / 2)+0.1$ \\
Example D & $2.5 \mathrm{~m}$ & $7.5 \mathrm{~s}$ & 0 & 0.06 \\
Example E & $2.5 \mathrm{~m}$ & $7.5 \mathrm{~s}$ & 0.25 & $0.13 \sin (0.5 t-\pi / 2)+0.13$ \\
Example F & $2.5 \mathrm{~m}$ & $7.5 \mathrm{~s}$ & 0.25 & $0.1 \sin (0.5 t-\pi / 2)+0.1$ \\
Example G & $4.0 \mathrm{~m}$ & $8 \mathrm{~s}$ & 0 & 0.06 \\
Example H & $4.0 \mathrm{~m}$ & $8 \mathrm{~s}$ & 0.25 & $0.13 \sin (0.5 t-\pi / 2)+0.13$ \\
Example I & $4.0 \mathrm{~m}$ & $8 \mathrm{~s}$ & 0.25 & $0.1 \sin (0.5 t-\pi / 2)+0.1$ \\
Example J & $9.0 \mathrm{~m}$ & $10 \mathrm{~s}$ & 0 & 0.06 \\
Example K & $9.0 \mathrm{~m}$ & $10 \mathrm{~s}$ & 0.25 & $0.13 \sin (0.5 t-\pi / 2)+0.13$ \\
Example L & $9.0 \mathrm{~m}$ & $10 \mathrm{~s}$ & 0.25 & $0.1 \sin (0.5 t-\pi / 2)+0.1$ \\
\hline
\end{tabular}

\section{Kinematic response of ERWEC under wave excitation}

In AQWA software, different wind and wave conditions are set to analyze the motion of the floating body of ERWEC under different sea conditions. The wave direction is along the positive $\mathrm{x}$-axis, the current speed is set to $0.5 \mathrm{~m} / \mathrm{s}$, and the wind speed is set to $1 \mathrm{~m} / \mathrm{s}$. The effective wave height and the average wave period of the different cases are shown in Table 3. 
Table 3. Effective wave height and average wave period for numerical simulation analysis

\begin{tabular}{ccc}
\hline & Effective wave height & Average wave period \\
\hline Example a & $1.5 \mathrm{~m}$ & $6.0 \mathrm{~s}$ \\
Example b & $2.5 \mathrm{~m}$ & $7.5 \mathrm{~s}$ \\
Example c & $4.0 \mathrm{~m}$ & $8.0 \mathrm{~s}$ \\
Example d & $9.0 \mathrm{~m}$ & $10.0 \mathrm{~s}$ \\
\hline
\end{tabular}

The analysis time is set to 30s, and the time history curve of the motion of the ERWEC float in six degrees of freedom is shown in Fig. 6. The six-degree-of-freedom motion data of the float can be used as the excitation of the ERWEC by waves, and thus the motion of the eccentric rotor under wave excitation conditions can be solved by Adams software.
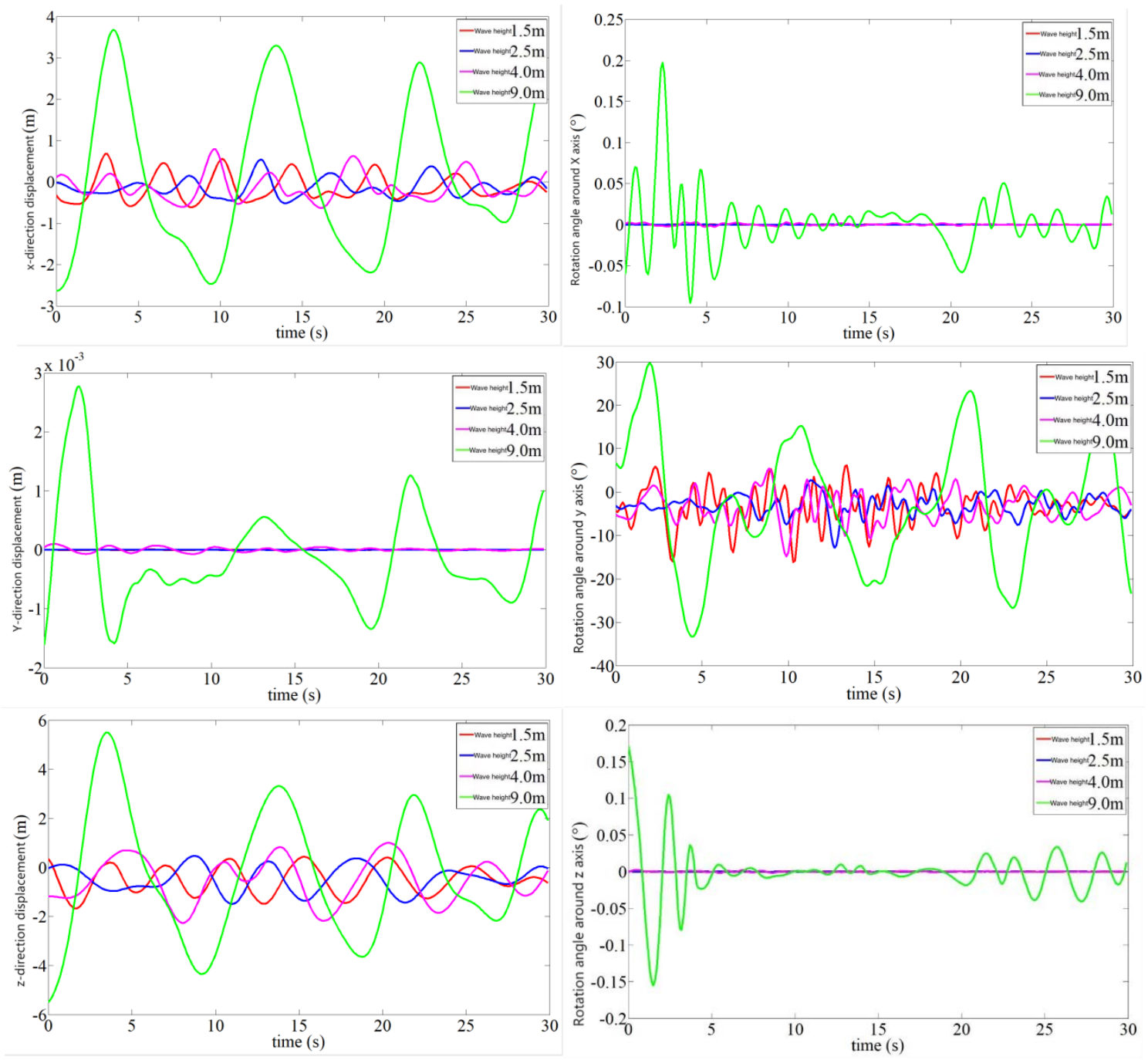

Figure 6. Six-degree-of-freedom motion response of ERWEC floats under different wave excitation conditions

\section{Power generation performance of ERWEC under different wave excitation conditions}

\subsection{Motion response of eccentric rotor}

The joint simulation analysis was carried out by Adams and Simulink to obtain the rotation speed of the eccentric rotor around the central axis under different wave excitation conditions. The rotation speed is shown in Figures 7 9. 


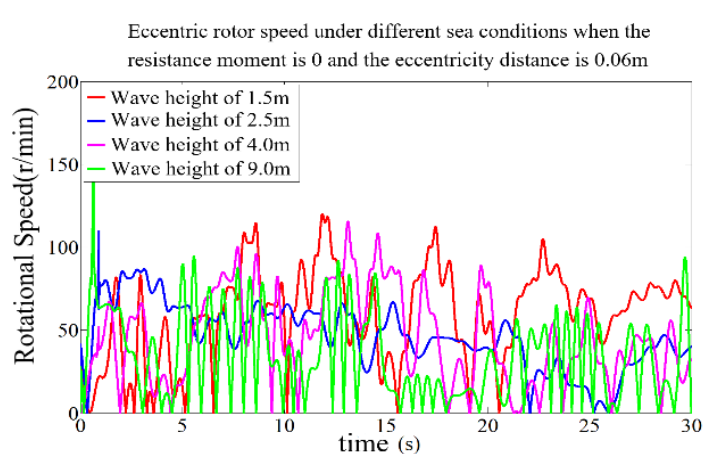

Figure 7. Analysis results of examples $\mathrm{A}, \mathrm{D}, \mathrm{G}$ and $\mathrm{J}$

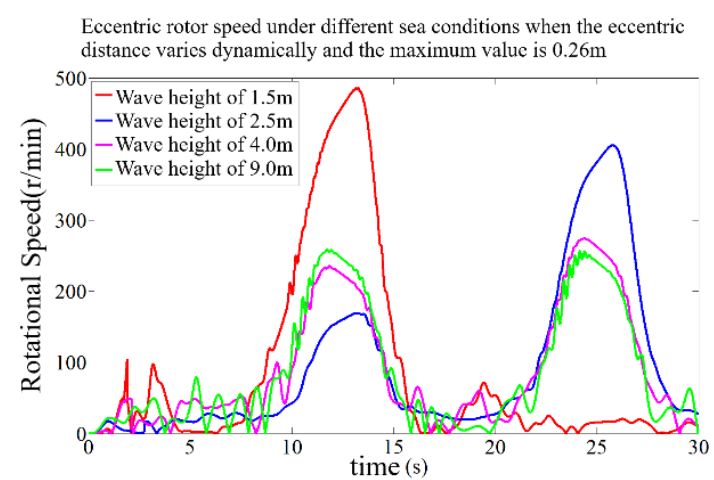

Figure 8. Analysis results of examples $\mathrm{B}, \mathrm{E}, \mathrm{H}$, and $\mathrm{K}$

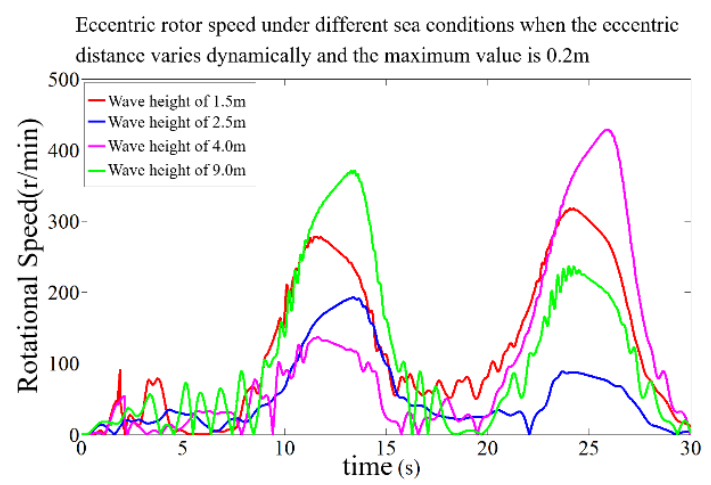

Figure 9. Analysis results of examples C, F, I and L

As can be seen from the figures, when the eccentric distance is constant, the rotational speed of the eccentric rotor is small, and the maximum speed is about $100 \mathrm{r} / \mathrm{min}$. When the resistive moment coefficient is the same, different eccentric rotor speeds can be obtained under the same wave conditions with different eccentric distance variation rules; under the same eccentric distance variation rules, different eccentric speeds can also be obtained with different wave excitation effects. For example, under the conditions of wave height of $4.0 \mathrm{~m}$, wave period of $8.0 \mathrm{~s}$ and resistance moment coefficient of 0.25 , the maximum eccentric rotor speed is about $300 \mathrm{r} / \mathrm{min}$ when the eccentric distance is varied by the rule of $0.13 \sin (0.5 \mathrm{t}-\pi / 2)+0.13$, and about $400 \mathrm{r} / \mathrm{min}$ when the eccentric distance is varied by the rule of $0.1 \sin (0.5 t-\pi / 2)+0.1$. When the eccentric distance is varied by the rule of $0.13 \sin (0.5 t-$ $\pi / 2)+0.13$, the maximum eccentric rotor speed is about $400 \mathrm{r} / \mathrm{min}$ under the condition of $2.5 \mathrm{~m}$ wave height and 8.0s wave period, and about 300 $/ \mathrm{min}$ under the condition of $9.0 \mathrm{~m}$ wave height and $10.0 \mathrm{~s}$ wave period.

The effective wave height is set to $1.5 \mathrm{~m}$, the average wave period is set to $6 \mathrm{~s}$, and the desired speed of the eccentric rotor is set to $500 \mathrm{r} / \mathrm{min}$. Under the action of the energy capture controller, and the obtained eccentric rotor speed is shown in Figure 10.

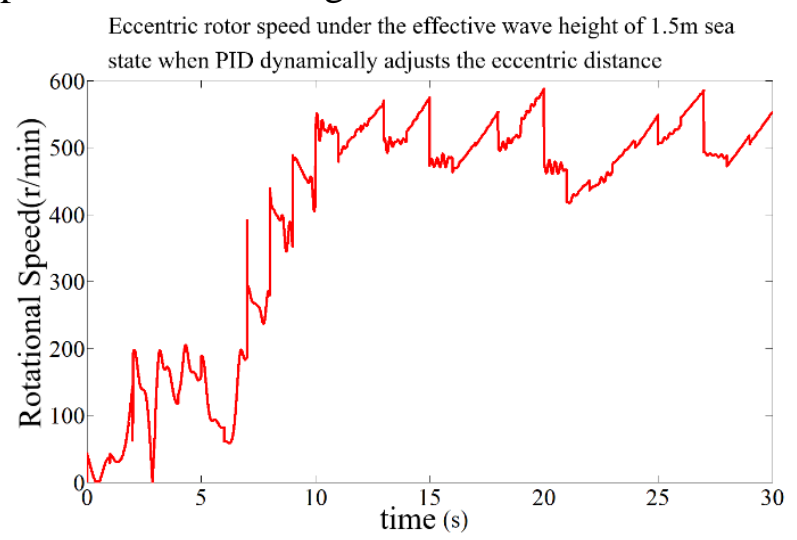


Figure 10. Eccentric rotor speed with energy capture controller

As can be seen from the figure, after adding the feedback controller, the eccentric rotor is able to maintain a high rotation speed. Although the rotation fluctuation is still large, the energy trapping effect is obviously improved.

\subsection{Energy trapping effect of eccentric rotor}

The power captured by the eccentric rotor can be calculated by equation (3):

$$
P_{G}=9550 n_{m} T_{m}
$$

where $n_{m}$ is the eccentric rotor speed and $T_{m}$ is the resistance moment between the eccentric rotor and the central shaft.

The power captured by the eccentric rotor for the different arithmetic constraints in the calculation is shown in Figures 11 and 12.

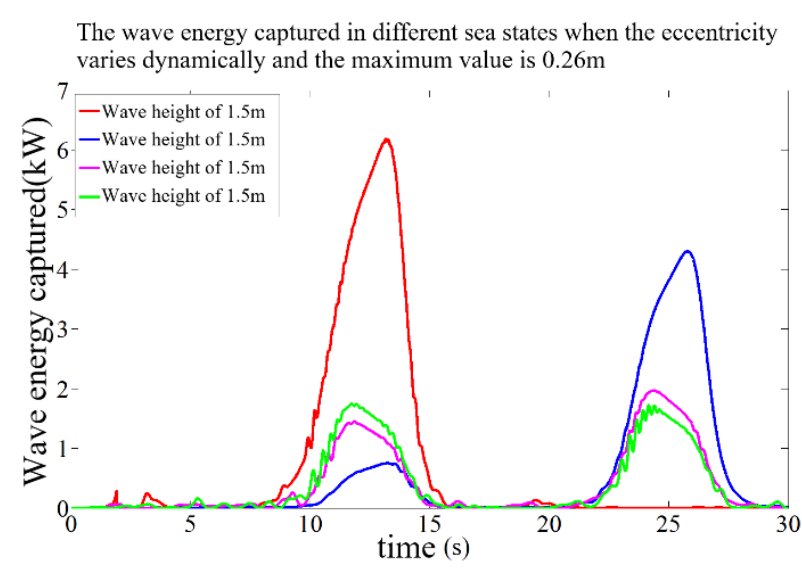

Figure 11. Analysis results of examples

$$
\mathrm{B}, \mathrm{E}, \mathrm{H} \text {, and } \mathrm{K}
$$

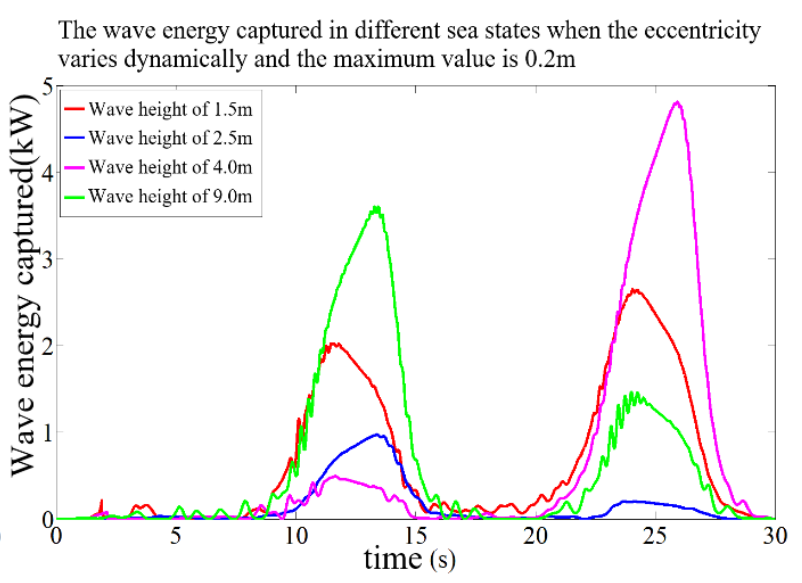

Figure 12. Analysis results of examples

C, F, I and L

It can be seen from the figure that the power captured by the eccentric rotor has a strong fluctuation, with the maximum power up to $6 \mathrm{~kW}$ when the eccentric distance is varied by the rule of $0.13 \sin (0.5 \mathrm{t}-$ $\pi / 2)+0.13$ and close to $5 \mathrm{~kW}$ when the eccentric distance is varied by the rule of $0.1 \sin (0.5 \mathrm{t}-\pi / 2)+0.1$. Further, the power captured by the eccentric rotor under the action of the energy capture controller is calculated, as shown in Figure 13.

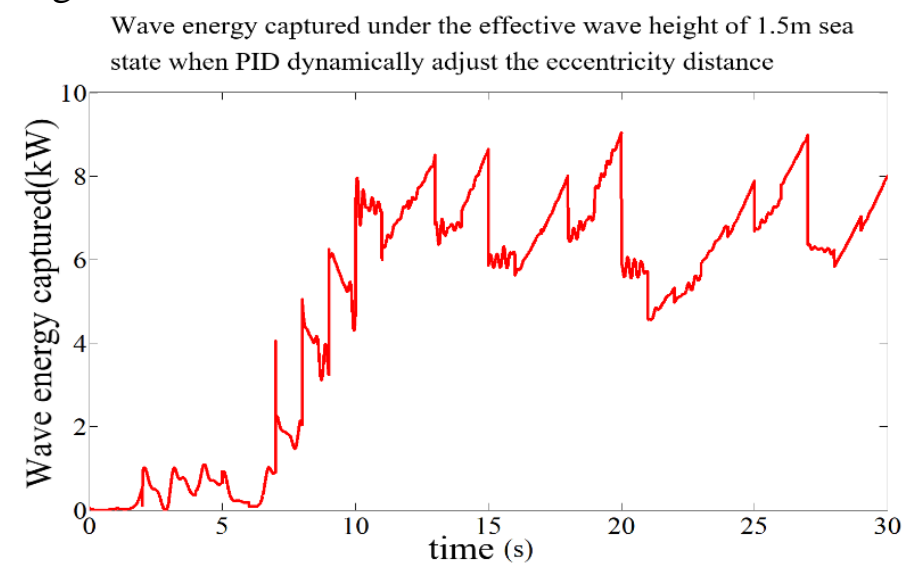

Figure 13. Power captured by the eccentric rotor with energy capture controller

Comparing Fig. 11 to Fig. 13, it can be seen that under the same wave excitation conditions, the introduction of the energy capture controller eliminates the "pulse" type fluctuations in the power and time curve and enables the captured wave energy power to be maintained at a high value.

\subsection{Energy conversion efficiency of wave energy converter}


The input power of wave energy can be approximated by equation (4):

$$
P_{W} \approx \frac{1}{2} H_{1 / 3}^{2} T P_{W}
$$

where $P_{W}$ is the wave energy flow density, $H_{1 / 3}$ is the effective wave height and $\bar{T}$ is the average wave period.

The feature size of ERWEC can be defined as:

$$
L=\sqrt{L_{a} L_{b}}
$$

where $L_{a}$ is the long axis of the ellipse and $L_{b}$ is the short axis of the ellipse.

The wave energy capture efficiency can be calculated as:

$$
\eta=\frac{P_{G}}{P_{W} L} \times 100 \%
$$

The eccentric rotor wave energy capture efficiency is calculated for different arithmetic constraints in Table 2, as shown in Figure 14 and Figure 15.

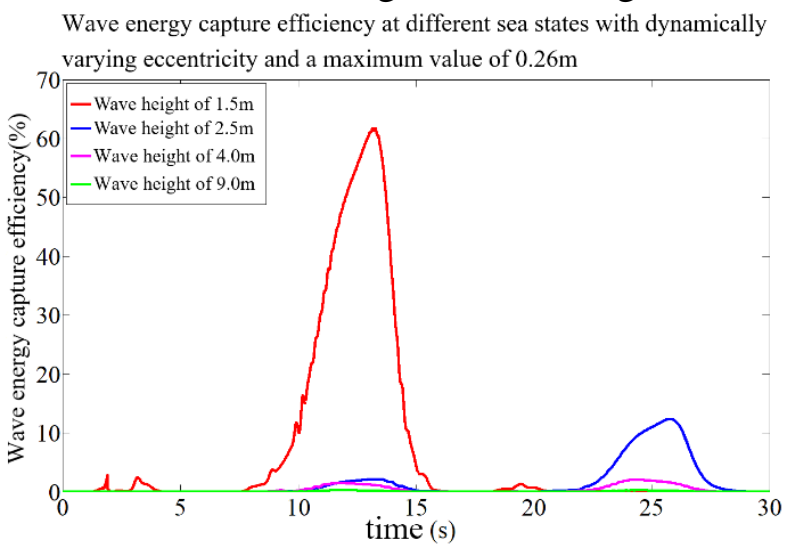

Figure 14. Analysis results of examples

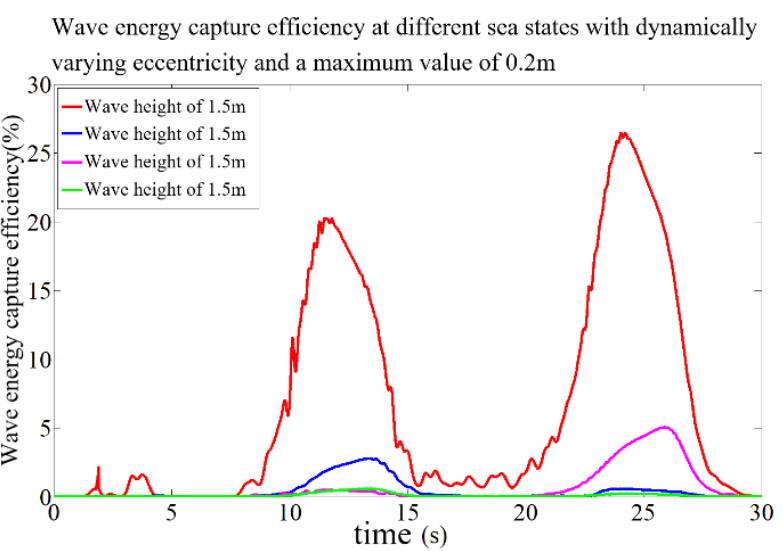

Figure 15. Analysis results of examples C, F, I and L

As can be seen from the figure, when the eccentricity distance is varied by the rule of $0.13 \sin (0.5 t-$ $\pi / 2)+0.13$ and $0.1 \sin (0.5 t-\pi / 2)+0.1$, it obtains the maximum energy capture efficiency both at an effective wave height of $1.5 \mathrm{~m}$ and an average wave period of $6.0 \mathrm{~s}$, and the peak efficiency can reach $60 \%$.

The energy capture efficiency of the eccentric rotor under the action of the energy capture controller is shown in Figure 16.

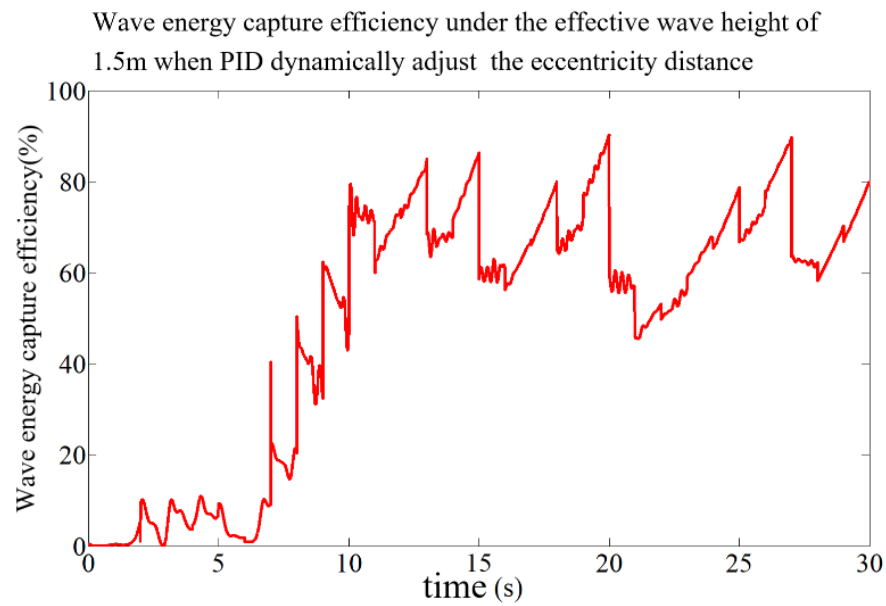

Figure 16. Energy capture efficiency of eccentric rotor with energy capture controller 
As can be seen from the figure, by active controlling of the eccentric distance of the eccentric rotor, a high wave energy capture efficiency can be obtained, and the efficiency is relatively stable, with an average efficiency of $70 \%$.

Further, the output power and time curves of the hydraulic pump and the hydraulic motor in the hydraulic PTO system under the action of the energy capture controller are analyzed, as shown in Figure 17. The energy capture efficiency, energy conversion efficiency and total efficiency of ERWEC are calculated as shown in Figure 18.

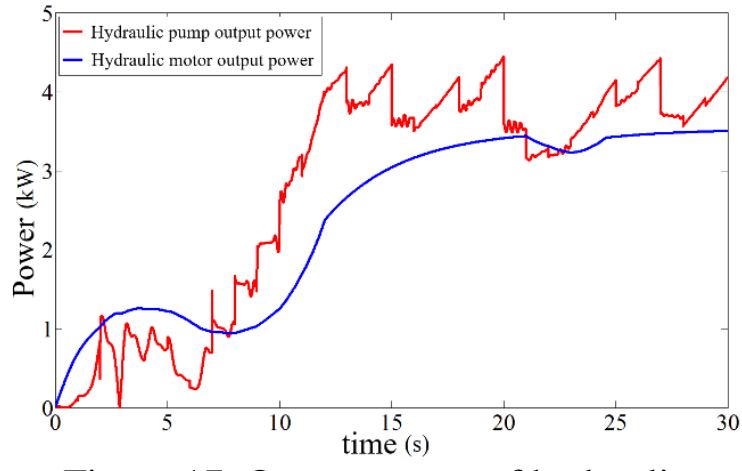

Figure 17. Output power of hydraulic pumps and motors under the regulation of energy catching controllers

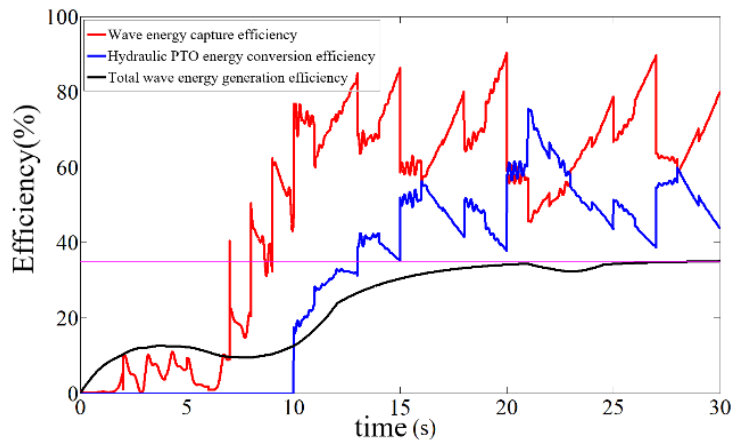

Figure 18. Energy conversion efficiency of ERWEC

It can be seen from the figure that the output power of the hydraulic motor is greater than that of the hydraulic pump before 10s due to the effect of the accumulator. After 10s, the pre-inflation pressure of the accumulator is completely released and the input power of the hydraulic PTO system comes entirely from the rotation of the eccentric rotor. Under the regulation of energy capture controller, the average output power of hydraulic pump is about $4 \mathrm{~kW}$, the average output power of hydraulic motor is about $3 \mathrm{~kW}$, the average wave energy capture efficiency of eccentric rotor reaches over $70 \%$, the energy conversion efficiency of hydraulic PTO reaches over $50 \%$ after the system runs for $15 \mathrm{~s}$, and the total efficiency of ERWEC system reaches more than 35\%.

\section{Conclusions}

In this paper, we propose a new form of ERWEC with high reliability to address the problem that high efficiency and high reliability are difficult to coexist in existing wave energy power generation devices. The numerical simulation model of ERWEC based on software of AQWA, Adams and AMESim was established, the rotor eccentricity's adaptive control strategy of sea state was proposed, the kinematic response of ERWEC floating body and eccentric rotor under wave excitation was analyzed, and the power generation performance of ERWEC under different wave excitation conditions was studied. The results show that there is a matching relationship between the variation rule of rotor eccentricity distances and wave conditions, and by dynamically adjusting the rotor eccentricity distance, a high wave energy capture efficiency can be obtained, and the energy capture efficiency is relatively stable.

The research work in this paper provides an important theoretical support for the development of high-efficiency and high-reliability wave energy generation devices. In the next step, the ERWEC physical model will be developed to verify the research conclusions obtained in this paper and to realize the engineering construction of high-efficiency and high-reliability wave energy power generation devices. 


\section{Acknowledgments}

This study was funded by the National Key Research and Development Program of China (Project No.: 2017YFE0115000), and Dr. Gang Xue of Shandong University is gratefully acknowledged for providing important supporting materials for the research work in this paper.

\section{References}

[1] Leijon J, Salar D, Engstrm J, et al. Variable renewable energy sources for powering reverse osmosis desalination, with a case study of wave powered desalination for Kilifi, Kenya. Desalination, 2020, vol 494 p 114669.

[2] Nguyen H, Wang C, Tay Z, et al. Wave energy converter and large floating platform I ntegration: A review. Ocean Engineering, 2020, p 213.

[3] Fadaeenejad M, Shamsipour R, Rokni S, et al. New approaches in harnessing wave energy: With special attention to small islands. Renewable \& Sustainable Energy Reviews, 2014, vol 29 pp 345354.

[4] Roland R, Francisco B, Elena O. International Renewable Energy Agency. Fostering a blue economy: Offshore renewable energy, 2020.

[5] Sun J, Li J, Ruan Z, et al. Simulation study on the effect of atmosphere-ocean-wave interactions on Typhoon Rammasun (2014) in the South China Sea. Journal of Atmospheric and Solar-Terrestrial Physics, 2020.

[6] Wang X, Li D, Bai Z, et al. The refined exploration and analysis method of wave energy resources around islands. Oceanologia et Limnologia Sinica, 2020, vol 51(05) pp 295-304.

[7] Sheng W. Wave energy conversion and hydrodynamics modelling technologies: A review. Renewable \& Sustainable Energy Reviews, 2019, vol 109 pp 482-498.

[8] Qiu S, Liu K, Wang D, et al. A comprehensive review of ocean wave energy research and development in China. Renewable \& Sustainable Energy Reviews, 2019, p 113.

[9] Zhang D, Li W, Lin Y. Wave energy in China: Current status and perspectives. Renewable Energy, 2009, vol 34(10) pp 2089-2092.

[10] Lv Q, Li D, Li D, et al, et al. Study on Energy Harvesting Efficiency for Wave Power Generating Platform Buoy of "Haiyuan 1" in Actual Sea Conditions. Journal of Zhejiang Ocean University(Natural Science), 2015, vol 34(04) pp 62-66.

[11] Falcão A, Henriques J. Oscillating-water-column wave energy converters and air turbines: A review. Renewable Energy, 2016, vol 85 pp 1391-1424.

[12] Lavidas G, Blok K. Shifting wave energy perceptions: the case for Wave Energy Converter (WEC) feasibility at milder resources. Renewable Energy, 2021.

[13] Cordonnier J, Gorintin F, De Cagny A, et al. SEAREV: Case study of the development of a wave energy converter. Renewable Energy, 2015, vol 80 pp 40-52. 